\title{
A Tunable Diode Laser System for Aircraft Measurements of Trace Gases
}

\author{
H. I. SCHIFF, ${ }^{1}$ D. R. KARECKI, AND G. W. HARRIS ${ }^{2}$ \\ Unisearch Associates Inc., Concord, Ontario, Canada \\ D. R. HASTIE \\ Department of Chemistry, York University, Ontario, Canada
}

\author{
G. I. MACKAY
}

Unisearch Associates Inc.. Concord, Ontario. Canada

\begin{abstract}
The advantages of tunable diode laser absorption spectrometry (TDLAS) for measuring trace atmospheric gases are universality, positive identification, good sensitivity, and rapid response time. A TDLAS system is described which is capable of making measurements on board an aircraft. The instrument was employed during the Chemical Instrumentation Test and Evaluation (CITE) 2 program to measure NO on 11 flights and $\mathrm{HNO}_{3}$ on five flights. Detection limits were determined to be 25 parts per trillion by volume [pptv] for $\mathrm{NO}_{2}$ and 75 pptv for $\mathrm{HNO}_{3}$ with response times of $3 \mathrm{~min}$. This was sufficient to permit measurements of $\mathrm{NO}_{2}$ in the free troposphere and $\mathrm{HNO}_{3}$ in the continental boundary layer a significant fraction of the time.
\end{abstract}

\section{INTRODUCTION}

Tunable diode laser absorption spectroscopy (TDLAS) has been shown to be a powerful and versatile technique for measuring trace gases in the atmosphere. It combines the universal applicability of infrared absorption with the high spectral resolution available with tunable laser diodes. A long path absorption cell provides the sensitivity required for the measurements. Reid et al. [1980] showed that TDL spectroscopy, in combination with a long path length absorption cell, a cooled $\mathrm{HgCdTe}$ detector, and second-harmonic detection, could measure the absorption from as little as 100 parts per trillion by volume [pptv] of $\mathrm{NO}_{2}$ in air, in the laboratory. This combination has been used in a number of field instruments [Schiff et al., 1983, 1987; Sachse et al., 1976, 1977, 1987; Ku et.al. 1975; Hinkley et al. 1976a, 1976b; Webster and May, 1987; Hastie and Miller, 1985]. Schiff et al. [1983]

\footnotetext{
${ }^{1}$ Also at Department of Chemistry, York University, North York, Ontario, Canada.

${ }^{2}$ Now at Max-Planck-Institut fur Chemie, Mainz, Federal Republic of Germany.
}

Copyright 1990 by the American Geophysical Union.

Paper number 89JD00762.

0148-0227/90/89JD-00762\$05.00 demonstrated the capability of their system to measure $\mathrm{NO}, \mathrm{NO}_{2}$, and $\mathrm{HNO}_{3}$ with detection limits of better than 500 pptv in the field. This instrument, with the addition of computerized data acquisition and analysis, was used to measure hydrogen peroxide with a detection limit of 600 pptv [Slemr et al., 1986].

We report here a substantially upgraded version of this instrument designed to make measurements of $\mathrm{NO}_{2}$ and $\mathrm{HNO}_{3}$ from an aircraft as part of the NASA Chemical Instrumentation Test and Evaluation (CITE) 2 program. The TDLAS technique was the only one of several techniques on this mission capable of measuring both species unequivocally. One of the major objectives of CITE 2 was to compare the performance of these techniques. The results of this comparison are given by Gregory et al. [this issue $(a),(b)$ ]. The data obtained by this instrument are used in these companion papers and are not repeated here.

\section{INSTRUMENT DESCRIPTION}

The spectrometer is similar to ground-based instruments described elsewhere [Schiff et al., 1987; Harris et al., 1989; Mackay et al., 1989]. The very low levels of $\mathrm{HNO}_{3}$ and $\mathrm{NO}_{2}$ expected in the free troposphere required an instrument with detection limits in the tens of pptv range. It was also necessary to reduce the weight and power requirements of the airborne instrument compared 
to those of the ground-based versions and to ensure that the optical system would be insensitive to inflight vibration as well as the shock of takeoff and landing .

The major changes improving the detection limits were the selection of state-of-the-art lead salt tunable diode lasers [TDL], the use of highquality, all-reflective optics, and a long path length absorption cell of the White-Horn-Pimentel design [Horn et al., 1971] incorporating mirrors with maximum reflectivity at $6 \mu \mathrm{m}$ (the absorption region for $\mathrm{HNO}_{3}$ and $\mathrm{NO}_{2}$ ). A reduction of $\sim 140$ $\mathrm{kg}$ in weight and $\sim 2000 \mathrm{~W}$ in power was achieved by replacing the closed cycle He cryocooler with a liquid $\mathrm{N}_{2}$ dewar to maintain the laser operating temperature.

TDLs of a short-cavity design (Laser Analytics, Bedford, Massachusetts) were specified to operate in a single frequency mode in the $1597-\mathrm{cm}^{-1}$ region for $\mathrm{NO}_{2}$ and in the $1722-\mathrm{cm}^{-1}$ region for $\mathrm{HNO}_{3}$ at temperatures of $77-110 \mathrm{~K}$ rather than the more conventional $30-60 \mathrm{~K}$.

The optical elements are mounted on an Al table top with a honeycomb core. The table is shock mounted to a welded Al frame bolted to the aircraft structure. For safety, a thin Al skin with access panels covers the entire spectrometer. The electronics are mounted in standard 19-inch (1 inch $=2.54 \mathrm{~cm}$ ) equipment racks designed for the aircraft. The vacuum pumps and compressed gases are mounted separately.

A schematic of the system is shown in Figure 1. The TDLs are mounted on a cold finger in a superinsulated, liquid nitrogen dewar (laser dewar). Two lasers are mounted on the cold finger; only one laser is operated at a time. A heater in conjunction with a temperature sensor maintains the laser temperature to within a few millikelvin. The laser is tuned by selecting the operating temperature and current. The dewar is mounted on translation

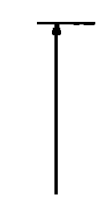

$50 \mathrm{~cm}$<smiles>[AlH2]</smiles><smiles>C1CCCC1</smiles>

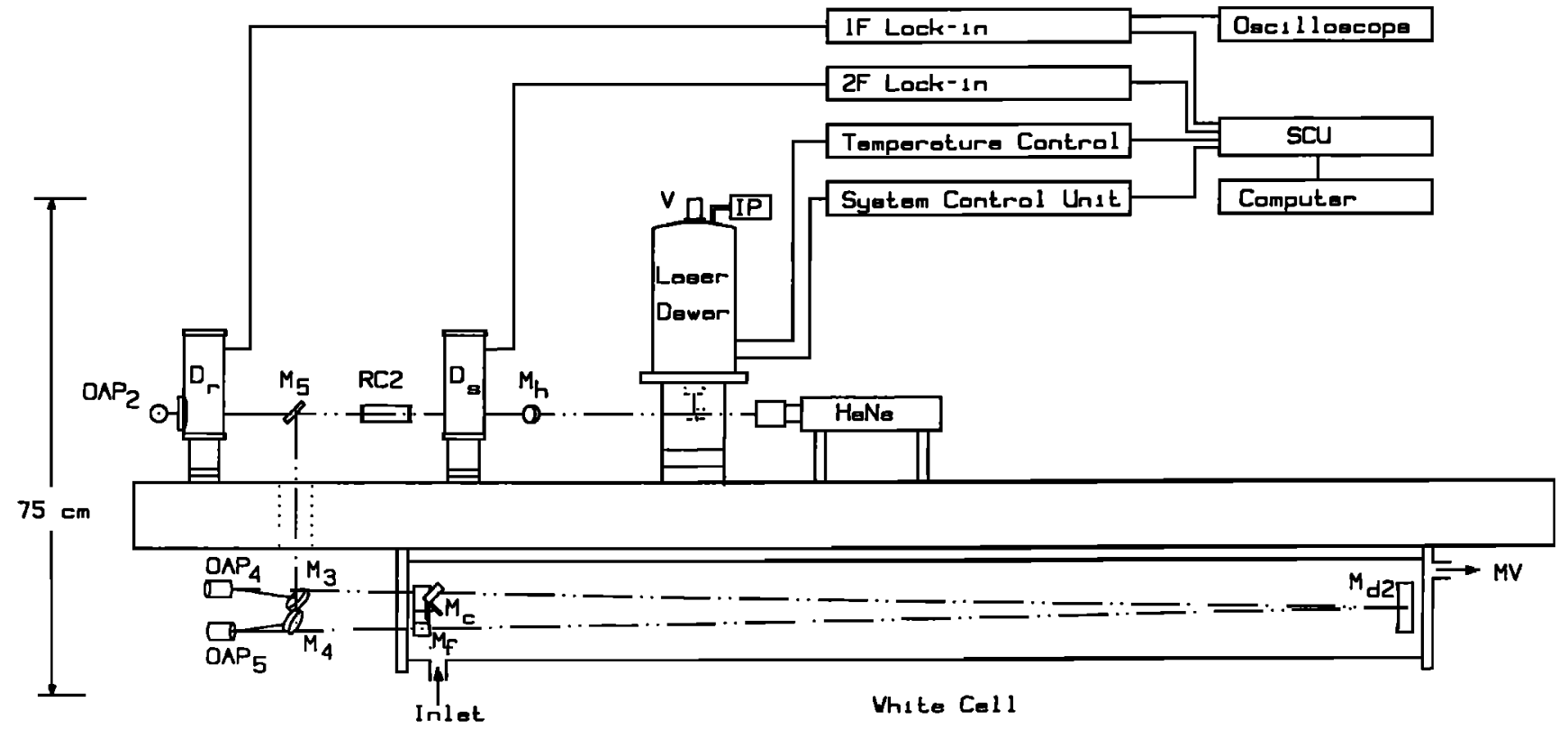

Fig. 1. Top and side view schematic layout of the airborne tunable diode laser absorption spectrometer system. Key: $\mathbf{M}_{1-5}$, beam directing mirrors; $\mathbf{O A P}_{1-5}$, off-axis parabolic mirrors; $\mathbf{M}_{f}$, in-focus White cell mirror; $\mathbf{M}_{\mathrm{d}}$ 2, out-of-focus White cell mirrors; $\mathbf{M}_{c}$, corner reflector; BS, 90/10 beam splitter; $R C 1$, reference line-locking cell; $\mathrm{RC2}^{\prime}, \mathrm{HNO}_{3}$ optical calibration cell; $\mathrm{D}_{r}$, infrared detector (reference side); $\mathbf{D}_{\mathbf{s}}$, infrared detector (sample side); $\mathrm{V}_{\text {, }}$ absolute pressure valve; IP, ion pump; MV, motorized throttle valve; He-Ne, helium-neon alignment laser. 
stages, which allow selection, alignment, and focusing of the appropriate laser. The hold time of the dewar is $10-24$ hours, depending on heater output and laser power dissipation.

The multipass cell is mounted below the table both for compactness and to distribute the weight evenly about the shock mounts on the edges of the table. OAP is a $90^{\circ}$ off-axis $f / 2.2$ parabolic mirror that collimates the radiation from the TDL into a beam of less than $15 \mathrm{~mm}$ in diameter. Most of the beam is reflected through an access hole in the table by a $90 \%$ reflecting beam splitter (BS). Plane mirror, M3, directs the beam to the off-axis, parabolic mirror, $\mathrm{OAP}_{4}$, which focuses the radiation into the $1.5-\mathrm{m}$ base path, $f / 22$ multipass cell. The beam exiting the cell is collimated by $\mathrm{OAP}_{5}$ and returned to the top of the table (by mirror M4) through a second access hole and passes through the calibration cell (RC2). The off-axis, parabolic mirror, $\mathrm{OAP}_{3}$, focuses it onto a cooled $\mathrm{HgCdTe}$ detector $\left(D_{r}\right)$.

Approximately $10 \%$ of the laser radiation passes through the beam splitter and a reference cell (RCl) filled with a high concentration of the species being monitored to a second $\mathrm{HgCdTe}$ detector (D2). The absorption observed from this cell is used to lock the frequency of the TDL.

The optical system is aligned by moving mirror M1 into the optical path. It can be rotated by precisely $90^{\circ}$ to direct a HeNe laser beam either to the TDL or through the rest of the optical system to the detectors.

The multipass cell is of the White-HornPimentel design [Horn et al., 1971] which incorporates a corner reflector to double the number of passes in the cell by translating the beam vertically and reflecting the beam back along an otherwise identical path through the cell. This arrangement reduces the astigmatism of the exit beam, more effectively utilizes the space on the front mirror, and decreases the sensitivity of the cell to misalignment of the incident beam and to vibration. The cell has a base path of $1.5 \mathrm{~m}$ and a volume of $28 \mathrm{~L}$. The mirrors were machined from 6-inch-diameter 1-inch-thick Pyrex blanks to a surface accuracy of one sixteenth of the HeNe laser wavelength. A four-layer, reflection-enhancing coating applied to the gold surface of the mirrors resulted in $\sim 99 \%$ reflectivity at $6 \mu \mathrm{m}$ (cf. $98.4 \%$ for normally protected gold mirrors). The input and output $\mathrm{BaF}_{2}$ windows are centered for 6-142 passes, which can be selected by adjusting a single mirror. For a detector noise limited system with $99 \%$ reflective mirrors the optimum number of passes through the cell is 94 , corresponding to a total path length of $141 \mathrm{~m}$. However, with present diode lasers, sufficient laser power is available at the detector to permit laser noise limited measurements, and the signal-to-noise $(\mathrm{S} / \mathrm{N})$ ratio continues to increase with increasing path length. The cell was designed to allow path lengths up to $213 \mathrm{~m} \mathrm{(142}$ reflections) and performed well at this maximum setting.
The mirrors are kinematically mounted on square aluminum plates with a single spring and 3-, 80-, or 64-threads-per-inch adjustment screws. The end plates are stabilized with 0.75 -inch-diameter Invar rods. A rubber gasket seals the Pyrex glass envelope to the end plates and allows for thermal contraction or expansion in the glass. The front end of the cell is rigidly mounted. The back end has some freedom of movement to allow for table contraction or expansion. To minimize adsorption of gases on the cell walls, the glass envelope is lined with a fluorinated ethylene propylene (FEP) Teflon sheet.

Air is sampled through a 1-m length of 6.35$\mathrm{mm}$ O.D. FEP Teflon tubing maintained at a temperature of $32^{\circ} \mathrm{C}$ by a heating element and sensor. This inlet tube is inserted into an aft facing probe, which extends through the fuselage beyond the aircraft boundary layer. The other end of the inlet tube is connected to a "T." One end of the "T" is attached to the multipass cell, and the other, through a solenoid valve, to a zero air tank for zero air measurements. For calibration the flow is directed through a scrubber and mass flowmeter to a junction where calibration gas can be introduced. The flow rate is controlled by a Teflon needle valve located immediately downstream of the calibration gas inlet. About $2 \mathrm{~m}$ of perfluoroalkoxy (PFA) Teflon tubing connects the needle valve to the multipass cell.

Two rotary vacuum pumps with a combined pumping speed of $1300 \mathrm{~L} / \mathrm{min}$ draw air through the multipass cell. The combination of a Baratron capacitance manometer pressure gauge and a motorized valve (MV) maintain the cell pressure at 25 torr. This reduces pressure broadening of the absorption line and minimizes the likelihood of interferences from other gases which may have absorption features near the frequency of the selected absorption line. The sample line resistance limits the maximum flow rate obtainable to about 20 standard liters per minute ( $\mathrm{slm}$ ) at sea level and $10 \mathrm{sim}$ at 16,000 feet. High flow rates are desirable to reduce the residence time and speed up equilibration of gases with the walls of the inlet system. At 20 slm and 25 torr, the residence time of the gas sample in the cell is about $3 \mathrm{~s}$.

The system control unit provides the current for the TDL. It has a ramp that sweeps the current at approximately $17 \mathrm{~Hz}$ to tune the TDL through an absorption feature. The ramp has a sawtooth shape with approximately $20 \mathrm{~ms}$ delay to allow the TDL temperature to recover to its starting value before each scan.

In addition, the system control unit provides a modulation current at $7.5 \mathrm{kHz}$ for frequency modulating the laser for second-harmonic $(2 f)$ detection [Reid et al., 1978; Sachse et al., 1976]. This technique improves the signal-to-noise ratio compared with direct absorption. The long path length provided by the multipass cell coupled with the use of $2 f$ detection permits absorptions in the $10^{-6}$ range to be measured. 
A lock-in amplifier is referenced to the current modulation and measures the modulated component of the signal from detector $D_{r}$ as the laser current is swept through the absorption line of the gas in the reference cell $(\mathrm{RCl})$. This produces a signal approximating the first derivative of the absorption feature. A comparator provides a logic transition, which is used to identify the line center for frequency stabilization. Corrections to the laser frequency are made by adjusting the laser operating temperature [Schiff et al., 1987; Harris et al., 1989].

The spectrometer operates under computer control. A small microprocessor in the system control unit provides a ramp voltage of 128 steps to drive the laser current across the absorption feature. After each scan the signal from the $2 f$ lock-in amplifier is added to the previous scans, and the line center is checked for any change from the setup values. If the TDL frequency has shifted, the temperature is adjusted until the initial frequency setting is reestablished. This corrects for ambient temperature variations, which cause instability in the temperature set point control electronics and in turn result in laser frequency drifts.

The computer acts as a terminal for the microprocessor and controls its functions. The computer also controls the solenoid valves used in calibration and zeroing and reads the voltages from the pressure and flow transducers. Measurement and calibration sequences are performed automatically, at operator-selected intervals. The raw spectra and results are archived to disk for later reanalysis. The ambient spectra are processed and least squares fitted to the calibration spectrum as described below. The ambient mixing ratios are displayed on the monitor and sent to a printer in real time.

Calibration sources were permeation type devices. For $\mathrm{NO}_{2}$ a commercially available wafer permeation device with a nominal permeation rate of $20 \mathrm{ng} \mathrm{min}-1$ at $40^{\circ} \mathrm{C}$ was used. For $\mathrm{HNO}_{3}$ a special permeation device was made in-house from Teflon tubing immersed in an acid bath of $\mathrm{HNO}_{3} / \mathrm{H}_{2} \mathrm{SO}_{4}$ with a permeation rate of approximately $140 \mathrm{ng} \mathrm{min}-1$. The temperature of both devices was stabilized in an oven with an electrical heater and thermoelectric cooler. $\mathrm{N}_{2}$ gas is passed continually over each permeation device at a rate of approximately 25 standard $\mathrm{mL} \mathrm{min}^{-1}$. The $\mathrm{NO}_{2}$ device is regularly calibrated by comparison with another permeation device calibrated through weight loss, and directly by $\mathrm{NO} / \mathrm{O}_{3}$ titration referenced to a National Bureau of Standards (NBS) traceable NO standard. The $\mathrm{HNO}_{3}$ device is calibrated by bubbling the gas mixture through a standard $\mathrm{NaOH}$ solution and following the neutralization with a pH meter. Measurements of the collected $\mathrm{NO}_{3}{ }^{-}$by ion chromatography confirmed the titration method.

In a typical measurement sequence the calibration spectrum is acquired first. The ambient airflow is directed through a flowmeter and Nylon scrubber. Since a Nylon scrubber is effective in removing $\mathrm{HNO}_{3}$, scrubbed ambient air can be used for the carrier gas during $\mathrm{HNO}_{3}$ calibration. During an $\mathrm{NO}_{2}$ calibration, excess zero air from a high purity zero air tank is added at the inlet to ensure $\mathrm{NO}_{2}$ free carrier gas. Calibration gas from the permeation device is added just downstream of the flowmeter and scrubber but in front of the Teflon needle valve. When the flows have become steady, a calibration spectrum is accumulated for 60 sec.

$\mathrm{NO}_{2}$ calibrations are performed regularly during a flight. Because of the long response time of the system for $\mathrm{HNO}_{3}$, only one standard addition calibration is performed per flight. To check system stability for $\mathrm{HNO}_{3}$ during a flight, an optical calibration is substituted involving introducing undiluted calibration gas, at the same pressure as in the White cell, into a short calibration cell (RC2) located in front of detector $D_{s}$. The effective mixing ratio is then calculated from the known mixing ratio of the gas in the calibration cell and the ratio of the two absorption cell lengths.

After acquisition of the calibration spectrum the calibration gas is turned off with background gas still flowing through the system. After a delay sufficient for all the calibration gas to leave the system, $60 \mathrm{sec}$ for $\mathrm{NO}_{2}$ and the short cell $\mathrm{HNO}_{3}$ calibration, the background spectrum is acquired for $60 \mathrm{~s}$, then subtracted point by point from the calibration spectrum. The resulting spectrum serves as a reference function for fitting ambient spectra.

Ambient spectra are then acquired and archived. The most recent background is subtracted, and the result is least squares fitted to the reference spectrum over a selected frequency range which includes the absorption feature. The linear correlation coefficient is calculated to indicate the goodness of fit. The Student's t-test is used to calculate the $95 \%$ confidence interval for the ambient mixing ratio obtained in the least squares fit, and this value is used as an indication of the precision of the measurement.

Another measure of the precision is determined experimentally by fitting the difference of two background spectra to the reference spectrum. The equivalent mixing ratio obtained from this subtraction is a measure of the minimum detectable level (MDL), providing the gas is not lost in the sampling process. Backgrounds are taken frequently, since changes in the background structure are the major source of uncertainty at concentrations approaching the MDL. On the basis of these measurements and the expected $\mathrm{NO}_{2}$ and $\mathrm{HNO}_{3}$ concentrations of CITE 2, the system was deemed capable of measuring the expected $\mathrm{NO}_{2}$ mixing ratios at most altitudes and $\mathrm{HNO}_{3}$ in the boundary layer. The performance of the instrument in these environments is discussed by Gregory et al. [this issue $(a),(b)]$.

The response time of the instrument is determined by the time over which the spectra were 
acquired. With a $60-\mathrm{s}$ acquisition time and a $30-\mathrm{s}$ dead time for computation, $\mathrm{NO}_{2}$ results can be obtained every $1.5 \mathrm{~min}$ using the most recent background. If backgrounds are taken more frequently, the response time must take into account the additional delay for stabilization of the flow of background gas. If five spectra were taken af ter each background, averaged, then subtracted from the average of the two adjacent background spectra, then the response time would be about 12 mins. This was the usual sequence used when submitting the $\mathrm{HNO}_{3}$ data at or near the detection limit. For $\mathrm{HNO}_{3}$ measurements with $\mathrm{S} / \mathrm{N}>3$, individual ( $1.5 \mathrm{~min}$ ) data points were submitted.

The accuracy of the $\mathrm{NO}_{2}$ measurements is estimated to be $\pm 15 \%$. $\mathrm{NO}_{2}$ permeation rates were determined by weight loss and checked by $\mathrm{NO} / \mathrm{O}_{3}$ titration with NO serving as the calibration standard. Weighing errors amount to $\pm 2 \%$, while the uncertainty in the $\mathrm{NO} / \mathrm{O}_{3}$ titration is about $\pm 5 \%$. Uncertainties in the measurement of the gas flow into which the $\mathrm{NO}_{2}$ calibration gas is diluted amount to $\pm 5 \%$. Additional calibration errors of $\pm 2 \%$ are caused by temperature variations of the permeation device.

The accuracy of the $\mathrm{HNO}_{3}$ measurements is estimated to be $\pm 20 \%$. The permeation rate is determined by potentiometric titration with standard $\mathrm{NaOH}$ solution. An uncertainty of $\pm 5 \%$ is attributable to the concentration of the standard $\mathrm{NaOH}$ solution, and $\pm 2 \%$ to the determination of the end point. Flow and temperature variation uncertainties are the same as for $\mathrm{NO}_{2}$. Sampling integrity is the major problem with measuring $\mathrm{HNO}_{3}$, since this gas is highly polar and absorbs readily on most surfaces. The response time of the system decreases with increasing flow rate of the sampled air through the system and is about $5 \mathrm{~min}$ for flow rates greater than $10 \mathrm{slm}$.

\section{EXPERIMENTAL RESULTS}

Laboratory studies showed that the MDL of the system, based on subtraction of background spectra, was of the order of $20 \mathrm{pptv}$ for $\mathrm{NO}_{2}$ and $75 \mathrm{pptv}$ for $\mathrm{HNO}_{3}$. Direct measurements of $\mathrm{NO}_{2}$ and $\mathrm{HNO}_{3}$ at mixing ratios near their detection limits were not possible, since no laboratory sources were available at these levels while the ambient concentrations at the laboratory site were in the part per billion by volume (ppbv) range for $\mathrm{NO}_{2}$ and below the detection limit of $\mathrm{HNO}_{3}$. The laboratory sources of $\mathrm{NO}_{2}$ in the 1-2 ppbv range and $\mathrm{HNO}_{3}$ sources in the $1.5-10 \mathrm{ppbv}$ range were used to establish that the response of the system to both species was linear with mixing ratio with a precision of $25 \mathrm{pptv}$ for $\mathrm{NO}_{2}$ and 100 pptv for $\mathrm{HNO}_{3}$. The ambient measurements established that $\mathrm{NO}_{2}$ and $\mathrm{HNO}_{3}$ absorption lines could be selected which were free of interferences from strong water vapor and absorption lines of other atmospheric constituents.
Preflight ambient air measurements also showed the MDL of $\mathrm{HNO}_{3}$ to be $\sim 75$ pptv.

Four test flights were conducted in April 1986 on a DC 3 aircraft operated by the Canada Centre for Remote Sensing in Ottawa, Ontario, Canada. Good measurements were obtained for $\mathrm{NO}_{2}$ in the 100-500 pptv levels encountered during all flights; no measurements were made of $\mathrm{HNO}_{3}$. A slight realignment of the optics, mostly to the absorption cell, was necessary after takeoff. If the ambient temperature changed significantly, a drift in background spectra caused by changing alignment was observed. Contact heaters applied to the table top were used with some success to maintain a constant operating temperature.

The spectrometer was next flown as part of the CITE 2 Global Tropospheric Experiment on an Electra aircraft operated by the Wallops Flight Facility of NASA. Measurements were made on 16 flights in all. Three of these were test flights made over the western Atlantic out of the Wallops facility. Two were transcontinental flights between Wallops and NASA Ames, from which the remaining nine flights were made. Seven of these were made over the eastern Pacific, and two were made over the continent. Two additional continental flights were made during the return to Wallops.

$\mathrm{HNO}_{3}$ was measured on one test flight, on two continental flights out of Ames, and on the two legs of the transit flight back to Wallops. $\mathrm{NO}_{2}$ was measured on all other flights. No periods of data loss were a result of instrument malfunction. In general, the instrument was fully functioning, and data were obtained within $15 \mathrm{~min}$ of takeoff.

$\mathrm{NO}_{2}$ data obtained in flight 9 out of NASA Ames are shown in Figure 2. These results are typical of the measurements made during the CITE 2 mission. The ambient spectrum is the average of two consecutive spectra acquired for $60 \mathrm{sec}$ each with a $30 \mathrm{sec}$ dead time for analysis. The background is the average of the two spectra taken immediately before and after the ambient spectra and were also acquired for $60 \mathrm{sec}$. This procedure provided one data point and one MDL every $7 \mathrm{~min}$.

The first 25 channels show a quick rise that is a poorly understood instrumental effect. These channels were not considered in the analysis. The remainder of the channels in the background spectrum of Figure 2 a have a smooth slope. To partially compensate for this slope, the background spectrum is subtracted from both the calibration and ambient spectra. Partial compensation for the slope still remaining may be made by subtracting off a best fit quadratic, resulting in the spectra shown in Figures $2 \mathrm{c}$ and $2 \mathrm{e}$. This quadratic subtraction can be shown to have little effect on the line shape if performed over a region significantly wider than the width of the absorption line.

The resultant calibration spectrum is fitted to the ambient spectrum. The calculation yields a mixing ratio of $72 \mathrm{pptv}$ with a correlation coefficient of 0.96 . If the difference between the two background 
$2 \mathbf{a}$

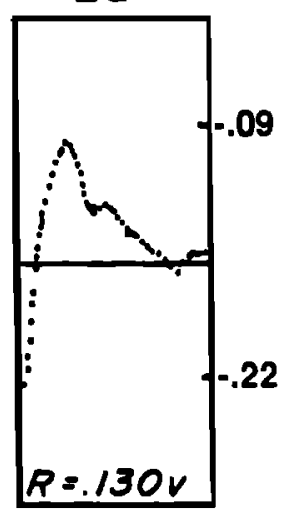

Bockground 2b

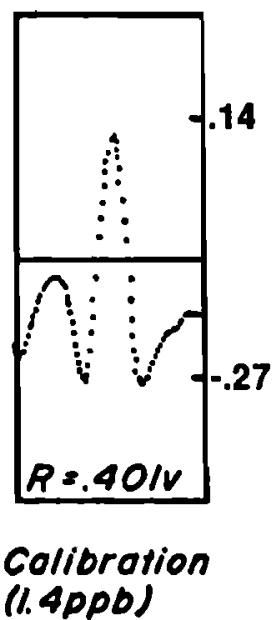

$2 c$

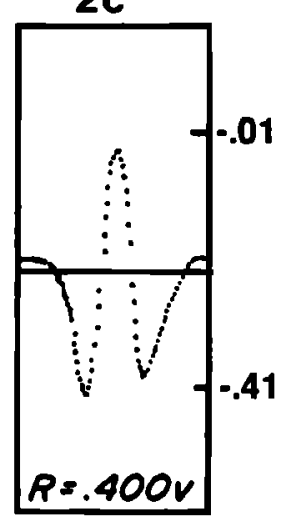

Calioration -Bockground

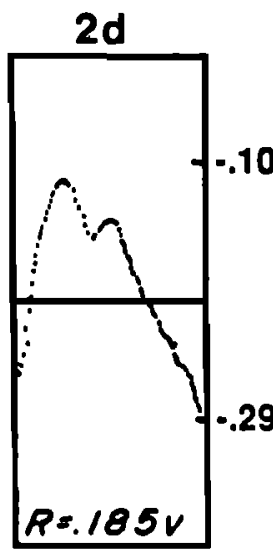

Ambient
$2 e$

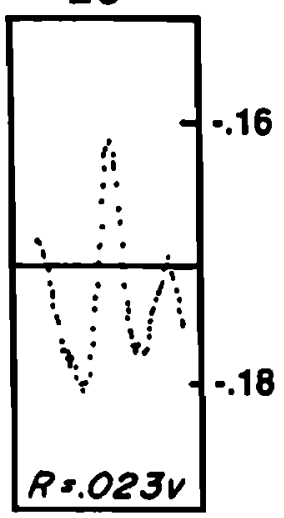

Ambient

-Bockground
$2 f$

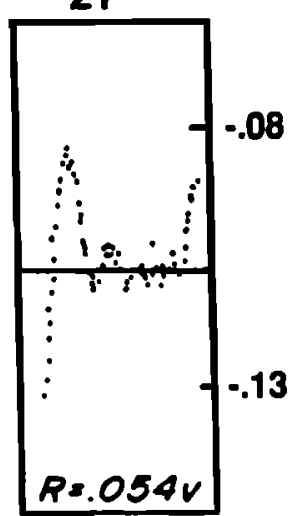

Backoround -Bockground

\section{2ppr $(r=.96) \quad-7 p p r(r=.08)$}

Fig. 2. Computer screen printouts for $\mathrm{NO}_{2}$ aircraft measurements representative of the results obtained in flight 9 out of NASA Ames. The $y$ ordinate is volts. $R$ is the magnitude of the signal in volte.

pairs taken immediately before and after the two ambient spectra is treated in the same fashion as ambient spectra, the MDL calculated is -7 pptv with a correlation coefficient of 0.08 , showing no correlation. The sequence of MDLs obtained after every two ambient acquisitions gives a good estimate of the detection limit over that period. For 10 MDLs calculated from background spectra acquired before and after the spectra shown in Figure 2 the average MDL is $0.7 \mathrm{pptv}$ with a standard deviation of $16 \mathrm{pptv}$. Consideration of all the data obtained for $\mathrm{NO}_{2}$ during the CITE 2 mission leads to an estimated detection limit of 25 pptv.

In contrast to $\mathrm{NO}_{2}$, sampling problems were encountered with the $\mathrm{HNO}_{3}$ measurements during the CITE 2 mission. These problems were evidenced by the lack of agreement between two methods of calibration used for this species. Because of the slow response time of the instrument to $\mathrm{HNO}_{3}$, the optical calibration method was used during flights, which avoided contaminating the system with calibration gas. Before and after each flight the system was calibrated by adding $\mathrm{HNO}_{3}$ calibration gas to scrubbed ambient air at the sampling inlet. Comparison between these calibration methods indicated that only about $25 \%$ of the calibration gas entered the optical path of the multipass cell for an $\mathrm{HNO}_{3}$ mixing ratio of $\sim 2$ ppbv. The actual sampling efficiency was found to be dependent on the sampling flow rate but was reproducible within the accuracy of the measurements for a fixed flow rate. The same comparisons made with similar ground-based systems showed agreement between the two calibration methods to better than $85 \%$. The source of the difference during the CITE 2 mission is unresolved. Since the sampling efficiency was reproducible and was determined for each flight, corrections have been applied to all $\mathrm{HNO}_{3}$ measurements.

Acknowledgments. We thank R. Navarro, the flight crew, and the maintenance personnel of the NASA/Wallops Island Flight Facility responsible for the Electra aircraft. Support was provided by the NASA Tropospheric Chemistry Program and the Atmospheric Environment Service of Environment Canada under the Unsolicited Grant Program, contract number 01SE.KM147-4-1639.

\section{REFERENCES}

Gregory, G. L., et al., An intercomparison of airborne nitrogen dioxide instruments, J. Geophys. Res., this issue (a).

Gregory, G. L., et al., An intercomparison of airborne nitric acid measurements, J. Geophyg. Res., this iseue (b).

Harris, G. W., G. I. Mackay, T. Iguchi, L. K. Mayne, H. I. Schiff, Measurements of formaldehyde in the troposphere by tunable diode laser absorption spectroscopy, J. Atmos. Chem., in press, 1989.

Hastie, D. R., and M. Miller, Balloon-borne tunable diode laser absorption spectrometer for multispecies trace gas measurements in the stratosphere, Appl. Opt., 24, 3694-3701 1985.

Hinkley, E. D., R. T. Ku, K. W. Nill, and J. F. Butler, Long path monitoring: advance instrumentation with a tunable diode laser, Appl. Opt., 15, 1653-1655 1976a.

Hinkley, E. D., R. T. Ku, and P. L. Kelly, Laser Monitoring of the Atmosphere, edited by D. Hinkley, chap. 6, pp. 237-295, Springer, New York, 1976 $\mathrm{b}$.

Horn, D., and G. C. Pimentel, 2.5-km low-temperature multiple-reflection cell, Appl. Opt., 10, 1892-1898, 1971.

Ku, R. T., E. D. Hinkley, and J. O. Sample, Long-path monitoring of atmospheric carbon monoxide with a tunable diode laser system, Appl. Opt., 14, 854-861, 1975.

Mackay, G. I., L. K. Mayne, and H. I. Schiff, Measurement of $\mathrm{H}_{2} \mathrm{O}_{2}$ and HCHO by tunable diode laser absorption spectroscopy during the 1986 carbonaceous species methods comparison study in Glendora, California, Aerosol Sci. Technol.; in press, 1990.

Reid, J., M. El-Sherbiny, B. K. Garside, and E. A. Balik, Sensitivity limits of a tunable diode laser spectrometer with application to the detection of $\mathrm{NO}_{2}$ at the $100 \mathrm{ppt}$ level, Appl. Opt., 19, 3349- 3353, 1980.

Sachse, G. W., F. Allario, G. F. Hill, C. Gross, R. K. Seals Jr., and B. S. Williams, Airborne carbon monoxide monitor using a tunable diode laser (instrument concept), Proceedinge of the 5th Annual Remote Sensing of Earth Resources Conference, 
edited by F. Shahrokhi, Univ, of Tenn. Space Inat., Tullahoma, pp. 315-331, 1976.

Sachse, G. W. G. F. Hill, L. A. Wade, and E. P. Condon, DACOM-A rapid, high sensitivity airborne carbon monoxide monitor, Paper presented at 4th Joint Conference on Sensing of Environmental Pollutants, Am. Chem. Soc., New Orleans, La., 1977.

Sachse, G. W., G. F. Hill, L. O. Wade, and M. G. Perry, Fastresponse, high-precision carbon monoxide sensor using a tunable diode laser technique, J. Geophys. Res., 92, 2071 $2081,1987$.

Schiff, H. I., D. R. Hastie, G. I. Mackay, T. Iguchi, and B. A. Ridley, Tunable diode laser systems for measuring trace gase in tropospheric air, Environ. Sci. Technol., 17, 352A-364A, 1983.

Schiff, H .I., G. W. Harris, and G. I. Mackay, Measurement of atmospheric gases by laser absorption spectrometry, in The Chemistry of Acid Rain: Sources and Atmospheric Processes, ACS Symp. Ser., vol. 349, edited by $R$. W. Johnson and G. E. Gordon, chap. 24, pp. 274-288, American Chemical Society, Washington, D. C., 1987 ..
Slemr, F., G. W. Harris, D. R. Hastie, G. I. Mackay, and H. I. Schiff, Measurement of gas phase hydrogen peroxide in air by tunable diode laser absorption spectroscopy, J. Geophys. Res., $\underline{\theta 1}, 6371-6378,1986$.

Webster, C. R. and R. D. May, Simultaneoue in-situ measurements and diurnal variations of $\mathrm{NO}, \mathrm{NO}_{2}, \mathrm{O}_{3}, \mathrm{jNO}_{2}$ $\mathrm{CH}_{4}, \mathrm{H}_{2} \mathrm{O}$ and $\mathrm{CO}_{2}$ in the 40 to $26-\mathrm{km}$ region using an open path tunable diode 7 aser spectrometer, J. Geophys. Res., 92, 11,931-11,950, 1987.

G.W Harris, Max-Planck-Institut für Chemie, 6500 Mainz, Federal Republic of Germany.

D. R. Hastie, Department of Chemistry, York University, North York, Ontario, Canada M3J 1 P3.

D. R. Karecki, G.I. Mackay and H. I. Schiff, Unisearch Associates Inc., 222 Snidercroft Road, Concord, Ontario, Canada LAK $1 B 5$.

(Received October 25, 1988;

revised April 11, 1989;

accepted April 11, 1989.) 